\title{
Is overall blockade superior to selective blockade of adrenergic receptor subtypes in suppressing left ventricular remodeling in spontaneously hypertensive rats?
}

\author{
Wen Qiang Chen ${ }^{1,3}$, Heng Cai ${ }^{2,3}$, Cheng Zhang ${ }^{1,3}$, Xiao Ping Ji ${ }^{1}$ and Yun Zhang ${ }^{1}$
}

To test the hypothesis that nonselective blockade of adrenergic receptor (AR) subtypes is superior to selective blockade of AR subtypes in suppressing left ventricular (LV) remodeling induced by hypertension. Sixty-four spontaneously hypertensive rats (SHR) were randomly divided into four groups: bisoprolol-treated, propranolol-treated, carvedilol-treated and no treatment groups ( $n=16$, each). Sixteen Wistar-Kyoto (WKY) rats served as a control group. Echocardiography and cardiac catheterization were carried out to record the mitral flow velocity ratio of $E$ wave to $A$ wave (E/A), LV mass index (LVMI), maximal rising (dp/dt $t_{\max }$ ) and falling $\left(-\mathrm{dp} / \mathrm{dt}_{\max }\right)$ rate of the LV pressure and LV relaxation time constant $(\tau)$. The mRNA and protein expression levels of $A R$, protein kinase $(P K)$ and G-protein subtypes, intracellular free calcium $\left(\mathrm{Ca}^{2+}\right)$ concentration and cardiocyte apoptoisis rate were determined. Three drug-treated groups showed higher velocity ratio of $E$ wave to $A$ wave $(E / A)$ and $-d p / d t_{\max }$ and lower systolic blood pressure (SBP), LVMI, $\tau$, apoptosis rate and intracellular free $\mathrm{Ca}^{2+}$ concentration than the no treatment group. The mRNA expression levels of AR- $\alpha_{1 B}$ in the carvedilol group were significantly lower than the other two drug-treated groups. The mRNA expression levels of AR- $\beta_{1}, A R-\beta_{2}$ and Gs $\alpha$ were significantly higher in the three drug-treated groups than in the no treatment group, with the expression levels of AR- $\beta_{2}$ being the highest in the carvedilol-treated group. The protein expression levels of PKA and PKC subtype $\alpha$ and $\delta$ were lower in the three drug-treated groups than in the no treatment group. Overall blockade of AR subtypes is not superior to selective blockade of AR subtypes in suppressing LV remodeling in SHR. Although carvedilol is the most effective in attenuating cardiocyte apoptosis, normalizing AR- $\alpha_{1 B}$ and Gs $\alpha$ expression and increasing AR- $\boldsymbol{\beta}_{\mathbf{2}}$ expression.

Hypertension Research (2010) 33, 1071-1081; doi:10.1038/hr.2010.121; published online 29 July 2010

Keywords: adrenergic receptor subtype; left ventricular remodeling; spontaneously hypertensive rat

\section{INTRODUCTION}

Left ventricular (LV) remodeling is the one of most important target organ damages in patients suffering with hypertension. Previous studies have shown that LV remodeling is an independent risk factor of cardiovascular events. ${ }^{1}$ An ideal antihypertensive therapy should be able to suppress LV remodeling, as well as to lower blood pressure. Although most current antihypertensive drugs are successful in achieving these goals, atenolol, a $\beta_{1}$-adrenoceptor antagonist, has been criticized for less successful protection of target organs and recent British and European guidelines have even withdrawn $\beta$-adrenoceptor antagonists from antihypertensive therapy simply because these drugs lack clinical evidence for reducing cardiovascular events. $^{2,3}$ However, with the advent of carvedilol with adrenergic receptor (AR)- $\alpha_{1}, A R-\beta_{1}$ and AR- $\beta_{2}$ antagonism and antioxidative property, there has been a continuing dispute about whether overall blockade is superior to selective blockade of AR subtypes in suppressing LV remodeling induced by hypertension, which has spurred further investigation on 'drug effects' with respect to 'class effects' among adrenoceptor antagonists.

Adrenergic receptors in the cardiovascular system include $\alpha$ and $\beta$ receptors, in which $\alpha$ receptor comprises AR- $\alpha_{1}$ and AR- $\alpha_{2}$ subtypes and $\beta$ receptor contains AR- $\beta_{1}$ and AR- $\beta_{2}$ subtypes. Multiple studies have confirmed the importance of the AR system in the development of LV remodeling secondary to hypertension. ${ }^{4}$ In experimental studies, norepinephrine has been reported to induce myocyte proliferation through its stimulation of AR- $\alpha_{1}$ and AR- $\beta$ in cultured cardiocytes. ${ }^{5}$ Consequently, suppression of AR- $\alpha_{1}$ and AR- $\beta$ has been considered important for attenuating the progress of cardiac remodeling. A major concern with the use of selective AR- $\beta$ antagonists is that AR- $\beta$ blockade may lead to intrinsic agonist stimulation of the AR- $\alpha$ subtype

${ }^{1}$ The Key Laboratory of Cardiovascular Remodeling and Function Research, Chinese Ministry of Education and Chinese Ministry of Health, Shandong University Qilu Hospital, Shandong, PR China and ${ }^{2}$ Department of Cardiology, the Second Affiliated Hospital of Shanxi Medical University, Shanxi, PR China ${ }^{3}$ These authors contributed equally to this work.

Correspondence: Dr Y Zhang, Shandong University Qilu Hospital, No.107, Wen Hua Xi Road, Jinan, Shandong 250012, PR China. E-mail: zhangyun@sdu.edu.cn

Received 16 January 2010; revised 24 May 2010; accepted 26 May 2010; published online 29 July 2010 
through feedback mechanisms, which may aggravate LV remodeling. For these reasons, overall blockade of AR subtypes seems to be superior to selective blockade of AR subtypes in the treatment of hypertension. This study, therefore, was designed to test the hypothesis that overall blockade of AR subtypes is superior to selective blockade of AR subtypes in suppressing LV remodeling secondary to hypertension by comparing the effects of AR- $\beta_{1}$ antagonist bisoprolol, AR- $\beta_{1}$ and $A R-\beta_{2}$ antagonist propranolol and AR- $\alpha_{1}, A R-\beta_{1}$ and AR- $\beta_{2}$ antagonist carvedilol in spontaneously hypertensive rats (SHR).

\section{METHODS}

\section{Animal model and experimental protocol}

Ten-week-old SHR $(n=64)$ and Wistar-Kyoto (WKY) rats $(n=16)$ (Beijing University, Beijing, China) were housed at a constant temperature $\left(24^{\circ} \mathrm{C}\right)$ in a room under $12 \mathrm{~h}$ dark $/ 12 \mathrm{~h}$ light cycles. The SHR were randomly divided into bisoprolol-treated group, propranolol-treated group, carvedilol-treated group and no treatment group ( $n=16$ for each group) that received daily oral dose of $2 \mathrm{mg} \mathrm{kg}^{-1}$ per day bisoprolol, $6 \mathrm{mg} \mathrm{kg}^{-1}$ per day propranolol, $6 \mathrm{mg} \mathrm{kg}^{-1}$ per day carvedilol and an equal amount of distilled water, respectively. WKY rats as a control group were given an equal amount of distilled water. On the basis of pharmacological properties, we selected bisoprolol (Merck Pharmaceuticals, Darmstadt, Germany) as an AR- $\beta_{1}$ antagonist, propranolol (Dong Feng Pharmaceuticals, Jinan, China) as an AR- $\beta_{1}$ and AR- $\beta_{2}$ antagonist and carvedilol (Qilu Pharmaceuticals, Jinan, China) as an AR- $\alpha_{1}$, AR- $\beta_{1}$ and AR- $\beta_{2}$ antagonist. All rats were treated for 24 weeks to ensure a sufficient timewindow for LV remodeling and therapeutic effects to take place. ${ }^{6}$

As the purpose of this study was to compare the efficacy of different AR antagonists in suppressing LV remodeling secondary to hypertension, the prerequisite for a chosen drug is to lower blood pressure to a normal level. The drug doses were determined by referring to previous studies on animal models of LV remodeling ${ }^{7-10}$ and by a preliminary study in which the drug doses were increased gradually from a low dose until the systolic blood pressure (SBP) in each drug-treated group reached the level of SBP as that of WKY rats. Our preliminary results showed that bisoprolol, propranolol and carvedilol at a dose of $2 \mathrm{mg} \mathrm{kg}^{-1}$ per day, $6 \mathrm{mg} \mathrm{kg}^{-1}$ per day and $6 \mathrm{mg} / \mathrm{kg} /$ day, respectively, were effective in normalizing SBP in SHR and thus, these doses were finally chosen for comparing the therapeutic effects of bisoprolol, propranolol and carvedilol in suppressing LV remodeling in SHR.

All animal care and experimental protocols complied with the Animal Management Rule of the Ministry of Public Health, People's Republic of China (documentation 55, 2001), and were approved by the Animal Care Committee of Shandong University.

\section{Blood pressure measurement}

During the entire period of treatment, body weight, heart rate and SBP were measured once a week in all the rats in a conscious state. SBP was measured using the tail-cuff method with a Rat Tail Manometer Tachometer System (RBP-1, Institute of Clinical Medicine, China-Japan Friendship Hospital, Beijing, China).

\section{Echocardiographic imaging}

Echocardiographic imaging involved use of an $8-\mathrm{MHz}$ transducer connected with an ultrasonic system (HP SONOS 5500, Hewlett Packard, Andover, MA, USA). All rats underwent general anesthesia with the chest shaved. Echocardiographic measurements were taken before treatment (at 10 weeks of age) and at the end of the treatment (at 34 weeks of age). LV end-diastolic and end-systolic diameters, LV ejection fraction, interventricular septum thickness and LV posterior wall thickness were measured by M-mode echocardiography, and LV mass index (LVMI) was calculated by the Devereux method and adjusted for body weight. ${ }^{11}$ The mitral flow velocities were recorded by the pulsed Doppler technique and the ratio of (E/A) velocitieswas calculated.

\section{Integrated backscatter analysis}

The integrated acoustic backscatter data from the interventricular septum, the posterior and the lateral walls of LV and the LV chamber were analyzed by the acoustic densitometry technique inherent in the ultrasonic system. The mean and peak ultrasonic intensity, cardiac cycle variation of integral backscatters and s.d. of the intensity of the LV wall and chamber were measured. The percentage of integrated backscatter was derived by calculating the ratio of the integrated backscatters of the LV wall to the integrated backscatters of the LV chamber.

\section{Cardiac catheterization}

Cardiac catheterization was carried out in all rats at the end of the treatment (at 34 weeks of age). With the animals under general anesthesia, a cardiac catheter (PE-50, Becton Dickinson, Franklin Lakes, NJ, USA) was introduced into the LV through the right common carotid artery and connected to a polygraph system (RM-6000, Nihon Kohden, Tokyo, Japan) to obtain the LV end-diastolic and the maximum rising (dp/dtmax) and falling $(-\mathrm{dp} / \mathrm{dtmax})$ rate of the $\mathrm{LV}$ pressure. The $\mathrm{LV}$ relaxation time constant $(\tau)$ was calculated by the Weiss method. ${ }^{12}$

\section{LVMI measurement}

Rats were euthanized by an overdose of intravenous pentobarbital. The LV mass was weighed after the LV was dissected from the heart, and LVMI was calculated by dividing LV mass by the body weight. Then the left ventricle was cut into four pieces at the papillary muscle level for histopathological, immunohistochemical, electronic microscopic and molecular biochemical studies.

\section{Histopathological and immunohistochemical analysis}

The LV samples were fixed in $1 \%$ formalin overnight and then cut into serial $5-\mu \mathrm{m}$ thick tissue sections for hematoxylin and eosin staining to observe morphological changes in myocardial cells and for Van Gieson staining to detect the degree of fibrosis. Stereology involving a video-microscopic system (Olympus BX50, Olympus, Tokyo, Japan) was used for quantitative analysis of the interstitial collagen in a given slide. Five high-power microscopic fields were randomly selected in each slide using a test-system composed of 36 test points $\left(P_{\mathrm{T}}\right)$ to derive volume density $\left(V_{\mathrm{vi}}\right)=P_{\mathrm{P}} / P_{\mathrm{T}}(\%)$ where $P_{\mathrm{P}}$ represents the points hitting the structure. ${ }^{13}$

The primary antibodies used were monoclonal antibodies for goat antimouse type I and III collagen fiber, goat anti-mouse protein kinase A (PKA) and protein kinase C (PKC) subtype $\alpha$ and $\delta$ (PKC- $\alpha$ and PKC- $\delta$ ) and goat anti-mouse p38-mitogen-activated protein kinase (p38-MAPK) (Sigma, St Louis, MO, USA). Positive staining was measured and expressed as mean percentage of the myocardium area in at least ten high-power fields $(\times 400$ magnification) by use of Image pro plus 5.1 software.

\section{Electronic microscopy}

The LV samples were fixed in $3 \%$ glutaral, post-fixed with $1 \%$ osmium tetroxide and examined by scanning electron microscopy (TEM-100, Electron, Joel, Tokyo, Japan) under $15 \mathrm{kV}$ accelerating voltage. Quantitative evaluation of the ultrastructural characteristics of interstitial collagen fibers (relative volumes) was carried out using the point-counting method. ${ }^{14}$ The ultrastructure of the myocardial cells was observed with transmission electron microscopy (JEM-1200EX, Electron, Joel, Tokyo, Japan). Samples were fixed with $0.2 \mathrm{~mol} / \mathrm{l}$ glutaraldehyde and osmium tetroxide and embedded into epon by standard procedures. Ultrathin sections were cut and doubly stained with uranyl acetate and lead citrate.

\section{Flow cytometry}

The heart was mounted on a Langendorff apparatus and perfused retrogradely with a $\mathrm{Ca}^{2+}$-free Joklik medium (Sigma) containing $0.01 \mathrm{mmoll}^{-1}$ ethylene glycol tetraacetic acid, followed by perfusion with isolation solution containing $0.8 \mathrm{mg} \mathrm{ml}^{-1}$ collagenase (type I, Worthington Biochemical, Lakewood, NJ, USA), and $0.08 \mathrm{mg} \mathrm{ml}^{-1}$ protease (type XIV, Sigma). Tissues were minced and poured through $250 \mu \mathrm{m}$ nylon mesh to collect the myocytes, which were resuspended in isolation solution and then washed with phosphate-buffered saline (PBS). Cell pellets were collected by centrifugation and resuspended in $0.5 \mathrm{ml}$ PBS. ${ }^{15}$ Then, $0.5 \mathrm{ml}$ of propidium iodide solution $\left(100 \mu \mathrm{g} \mathrm{ml}^{-1}\right.$ in PBS) was added and the mixture was allowed to stand on ice for $30 \mathrm{~min}$. The myocardial cells $\left(1 \times 10^{6} \mathrm{ml}^{-1}\right)$ were analyzed with a FACScan flow cytometer (Becton Dickinson, San Jose, CA, USA) and distribution of the cell cycle phases 
was determined by means of ModFit LT software (Verity Software House, Topsham, ME, USA). The population of apoptotic cells was quantified by annexing with V-FITC staining (Bender Medsystems, Boehringer Mannheim, Germany) and the apoptosis rate was calculated.

\section{Intracellular $\mathrm{Ca}^{2+}$ concentration assay}

Intracellular $\mathrm{Ca}^{2+}$ concentration was measured in Fluo-3/AM-loaded myocardial cells by use of flow cytometry as previously described. ${ }^{16}$ The myocardial cells were harvested and resuspended in PBS buffer without $\mathrm{Ca}^{2+}$ and $\mathrm{Mg}^{2+}$. A $490 \mu \mathrm{l}$ myocardial cell $\left(4 \times 10^{6} \mathrm{ml}^{-1}\right)$ suspension was then incubated with $10 \mu$ Fluo-3/AM buffer ( $1.0 \mathrm{~mm}$, Dojindo, Kumamoto, Japan) for $30 \mathrm{~min}$ at $37^{\circ} \mathrm{C}$, then washed twice and resuspended in PBS buffer. A FACScan flow cytometer (Becton Dickinson) was used to measure the fluorescence intensity. With the same process, the fluorescence intensity was measured in another sample containing $500 \mu \mathrm{l}$ of myocardial cell suspension. Intracellular free $\mathrm{Ca}^{2+}$ concentration was calculated as mean fluorescence intensity with Fluo-3/AM divided by mean fluorescence intensity without Fluo-3/AM.

\section{Quantitative RT-PCR}

Tissue samples were frozen with liquid nitrogen. Total RNA was extracted and mRNA expression of $\alpha_{1 \mathrm{~A}}$-AR, $\alpha_{1 \mathrm{~B}}-\mathrm{AR}, \alpha_{1 \mathrm{D}}-\mathrm{AR}, \beta_{1}-\mathrm{A}$ and $\beta_{2}$-AR and G-protein (Gs $\alpha, \mathrm{Gi} \alpha$ and $\mathrm{Gq} \alpha$ ) of the myocardium was determined by quantitative RTPCR with use of LightCycler (Roche Applied Science, Indianapolis, IN, USA) following the manufacturer's instruction. The mRNA sequences were obtained from the GenBank and the primer sequences of each gene were shown in Table 1. Quantitative values were obtained from the threshold cycle value, the point at which a significant increase of fluorescence is first detected, and the data were analyzed with the $2^{-\Delta \Delta \mathrm{CT}}$ method. ${ }^{17}$ Experiments were carried out in triplicate for each data point. The transcript number of glyceraldehyde 3-phosphate dehydrogenase was quantified as an internal control.

\section{Western blotting analysis}

Total protein was extracted and detected by western blot. The protein expression of type I and III collagen, PKC- $\alpha$, PKC- $\delta$ and p38-MAPK was shown by the ratio of integral optical density between these values and $\beta$-actin.

\section{Statistical analysis}

Values are expressed as mean \pm s.d. Comparison of continuous variables among multiple groups was performed by analysis of variance with ANOVA and post hoc comparisons were made using lysergic acid diethylamide test. The

Table 1 Primer sequences and gene lengths for RT-PCR

\begin{tabular}{|c|c|c|}
\hline Genes & Primer sequences & Primer length (bp) \\
\hline \multirow[t]{2}{*}{$\beta$-actin } & 5'-CAGCACTGTGTTGGCATAGAG-3' & 327 \\
\hline & 5'-AAGATCCTGACCGAGCGTGG-3' & \\
\hline \multirow[t]{2}{*}{$\beta_{1}$ adrenoceptor } & 5'-CTCACCAACCTCTTCATCATG-3' & 522 \\
\hline & 5'-GAAGCGGCGCTCGCAGCTGTCG-3' & \\
\hline \multirow[t]{2}{*}{$\beta_{2}$ adrenoceptor } & 5'-GAGACCCTGTGCGTGATTGC-3' & 387 \\
\hline & 5'-CCTGCTCCACCTGGCTGAGG-3' & \\
\hline \multirow[t]{2}{*}{$\alpha_{1 A}$ adrenoceptor } & 5'-CGAGAGAAGAAAGCTGCCAAG-3' & 299 \\
\hline & 5'-TCCTGGCTGGAGCATGGGTA-3' & \\
\hline \multirow[t]{2}{*}{$\alpha_{1 B}$ adrenoceptor } & 5'-ATCGTGGCCAAGAGGACCAC-3' & 265 \\
\hline & 5'-CGGGAGAGCGATGAAGAAGG-3' & \\
\hline \multirow[t]{2}{*}{$\alpha_{1 D}$ adrenoceptor } & 5'-CGTGTGCTCCTTCTACTACC-3' & 302 \\
\hline & 5'-GCACAGGACGAAGACACCCAC-3' & \\
\hline \multirow[t]{2}{*}{ Gs $\alpha$-protein } & 5'-CAGAAGGACAAGCAGGTCTAC-3' & 318 \\
\hline & 5'-GTTCATCACGCTCAGAATG-3' & \\
\hline \multirow[t]{2}{*}{ Gi $\alpha$-protein } & 5'-GGAGAATCAGGGAAGAGC-3' & 213 \\
\hline & 5'-ACAGGACAGTGCGAACAG-3' & \\
\hline \multirow[t]{2}{*}{ Gqa-protein } & 5'-AGAGTGGCAAGAGTACCTTC-3' & 495 \\
\hline & 5'-TTCTCTCTGACCTTTGGC-3' & \\
\hline \multirow[t]{2}{*}{ Gß-protein } & 5'-TGCCTTGTGGGACATTGAG-3' & 378 \\
\hline & 5'-AAGTCATCATAGCCAGCAAAG-3' & \\
\hline
\end{tabular}

relation between variables was estimated with use of Pearson correlation. A $P<0.05$ was considered significant. All analyses involved use of SPSS version 13.0 (SPSS, Chicago, IL, USA).

\section{RESULTS}

Effects on body weight and blood pressure

In total, nine rats (three in WKY group, one each in the bisoprololtreated and carvedilol-treated groups and two in the propranololtreated and no treatment groups) died of anesthetic accident, aspirated pneumonia or upper gastrointestinal bleeding during the experiment.

There was no significant difference in body weight and heart rate among WKY, no treatment and three drug-treated groups either at baseline or 24-weeks after treatment. The SBP did not differ among all five groups of rats at baseline, but was significantly lower in the WKY and three drug-treated groups than in the no treatment group 24-weeks after treatment. In contrast, SBP did not differ between the WKY and three drug-treated groups 24-weeks after treatment (Table 2).

\section{Effects on echocardiographic measurements}

There was no significant difference in LV end-diastolic and endsystolic diameters and LV ejection fraction among five groups of rats before and after treatment. Twenty-four weeks after treatment, LVMI was significantly higher but the E/A ratio was lower in the no treatment group than in the WKY group $(P<0.01$, Figure 1$)$. The LVMI was significantly lower, but E/A ratio was higher in the three drug-treated groups than in the no treatment group (all $P<0.05)$. The LVMI and E/A ratio did not significantly differ among the three drugtreated groups.

\section{Effects on integrated backscatter measurements}

Percentage of integrated backscatter in the interventricular septum and LV posterior and lateral walls was significantly higher, whereas cardiac cycle variation of integral backscatters in the interventricular septum and LV posterior wall was lower in the no treatment group than in the WKY group (Table 3). The three drug-treated groups did not differ from the no treatment group or from each other in percentage of integrated backscatter and cardiac cycle variation of integral backscatters in the interventricular septum and LV posterior and lateral walls.

\section{Effects on hemodynamic measurements}

Compared with the WKY group, the no treatment group showed higher LV end-diastolic and $\tau$ and lower $-\mathrm{dp} / \mathrm{dt}_{\max }$, the bisoprololtreated and propranolol-treated groups showed higher $\tau$ and lower $-\mathrm{dp} / \mathrm{dt}_{\max }$ and the carvedilol-treated group showed only lower $-\mathrm{dp} / \mathrm{dt}_{\max }$. The three drug-treated groups showed higher $-\mathrm{dp} / \mathrm{dt}_{\max }$ and lower $\tau$ than the no treatment group (Figure 2). In contrast, none of these hemodynamic parameters showed significant difference among the three drug-treated groups.

\section{Effects on histopathological changes}

Pathological measurement of LVMI of the no treatment group was significantly higher than that of the WKY and three drug-treated groups, with no significant difference among the three drug-treated groups (Figure 1). In the no treatment group, LVMI measured by echocardiography and pathology showed a good correlation $(r=0.69$, $P<0.01$ )

Hematoxylin and eosin staining of the myocardium showed increased volume of myocardial cell nuclei in the no treatment 
Table 2 Body weight, heart rate (HR) and systolic blood pressure (SBP) at baseline and after treatment

\begin{tabular}{|c|c|c|c|c|c|c|}
\hline \multirow[b]{2}{*}{ Groups } & \multicolumn{2}{|c|}{ Weight (g) } & \multicolumn{2}{|c|}{$H R\left(\min ^{-1}\right)$} & \multicolumn{2}{|c|}{$\mathrm{SBP}\left(\mathrm{mm} \mathrm{Hg}^{-1}\right)$} \\
\hline & Baseline & Week24 & Baseline & Week 24 & Baseline & Week 24 \\
\hline No treatment $(n=14)$ & $208.32 \pm 3.74$ & $270.78 \pm 4.77$ & $362.14 \pm 37.82$ & $379.22 \pm 56.83$ & $133.21 \pm 22.57$ & $218.21 \pm 36.68^{* *}$ \\
\hline Bisoprolol-treated $(n=15)$ & $210.17 \pm 5.90$ & $276.93 \pm 5.98$ & $366.10 \pm 35.36$ & $363.41 \pm 39.50$ & $137.70 \pm 25.14$ & $115.52 \pm 37.13^{\#}$ \\
\hline Propranolol-treated $(n=14)$ & $209.70 \pm 4.72$ & $283.85 \pm 4.95$ & $372.88 \pm 36.17$ & $352.57 \pm 58.82$ & $134.94 \pm 23.09$ & $119.75 \pm 41.37^{\#}$ \\
\hline
\end{tabular}

Abbreviation: WKY, Wistar-Kyoto.

${ }^{* *} P<0.01$, vs. WKY group at week $24 ;{ }^{\#} P<0.05$, vs. no treatment group at week24.
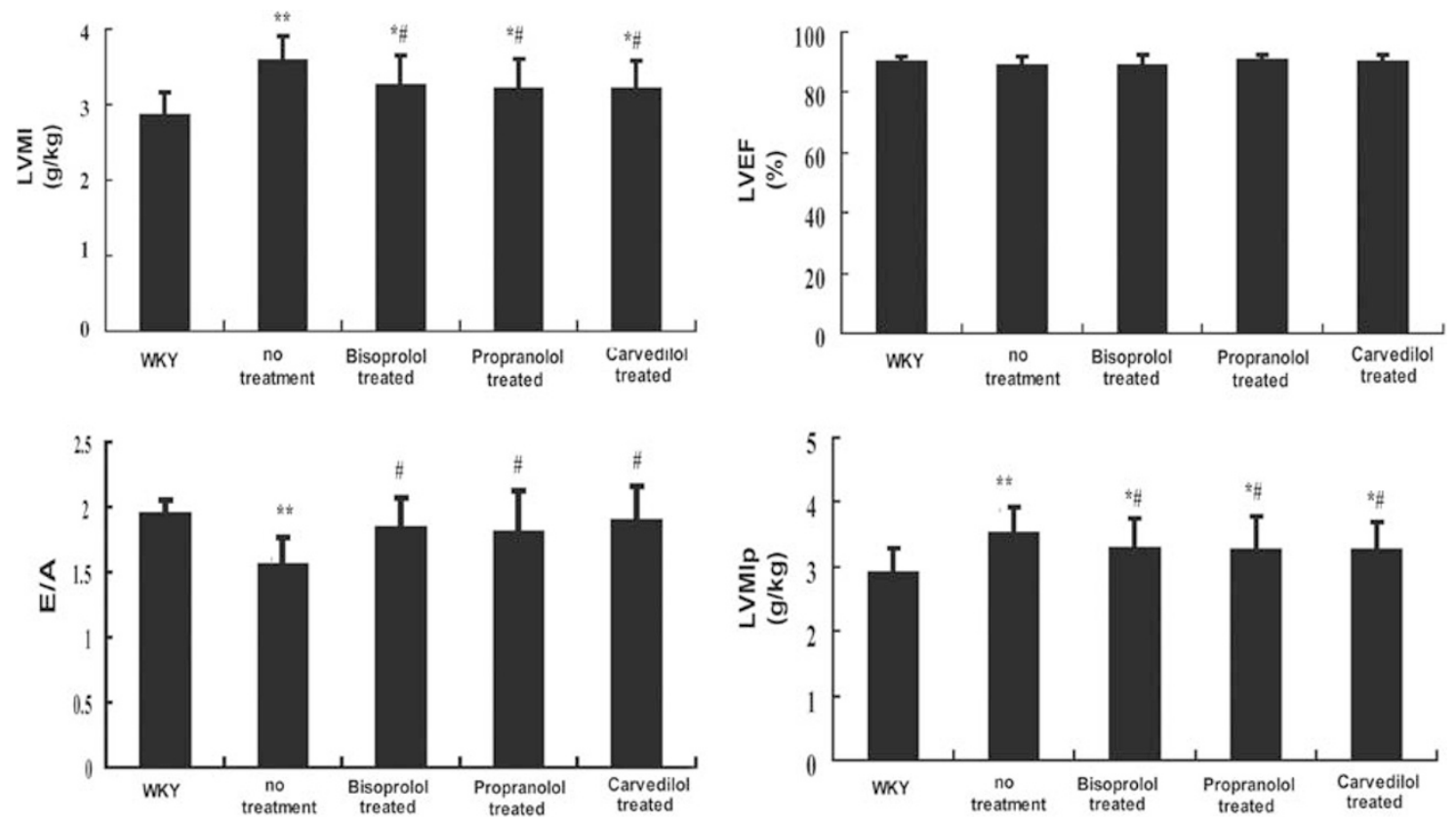

Figure 1 Echocardiographic and pathological measurements in five groups of rats. Left ventricular mass index (LVMI) was higher in the no treatment and three drug-treated groups than in the Wistar-Kyoto (WKY) group, but was lower in the three drug-treated groups than in the no treatment group. E/A ratio was lower in the no treatment group than in the WKY and three drug-treated groups. Pathological measurement of LVMI showed similar differences among the five groups of rats as LVMI. ${ }^{*} P<0.05$, ${ }^{* *} P<0.01$, vs. WKY group; $P P<0.05$, vs. no treatment group.

Table 3 Echocardiographic measurements of integrated backscatters of myocardium

\begin{tabular}{|c|c|c|c|c|c|c|}
\hline \multirow[b]{2}{*}{ Groups } & \multicolumn{3}{|c|}{$I B \%$} & \multicolumn{3}{|c|}{$C V I B(d B)$} \\
\hline & IVS & $\angle V P W$ & $\angle V L W$ & IVS & $\angle V P W$ & $L V L W$ \\
\hline No treatment $(n=14)$ & $1.59 \pm 0.34^{*}$ & $1.62 \pm 0.29 *$ & $1.46 \pm 0.21^{*}$ & $4.52 \pm 1.83^{*}$ & $5.82 \pm 2.05^{*}$ & $5.65 \pm 2.13$ \\
\hline Bisoprolol-treated $(n=15)$ & $1.55 \pm 0.38$ & $1.58 \pm 0.32$ & $1.44 \pm 0.27$ & $4.86 \pm 2.12$ & $6.15 \pm 2.34$ & $5.98 \pm 2.23$ \\
\hline Propranolol-treated $(n=14)$ & $1.52 \pm 0.33$ & $1.56 \pm 0.24$ & $1.41 \pm 0.35$ & $4.98 \pm 1.94$ & $6.18 \pm 2.41$ & $5.87 \pm 2.04$ \\
\hline
\end{tabular}

Abbreviations: CVIB, cycle variation of integral backscatters; IB\%, percentage of integrated backscatters; IVS, interventricular septum wall thickness; LVLW, left ventricular lateral wall; LVPW, left ventricular posterior wall thickness; WKY, Wistar-Kyoto.

$* P<0.05$, vs. WKY group.

group, which was significantly improved in the three drug-treated groups. The expression level of collagen indicated by Van Gieson staining was significantly higher in the no treatment group than in the WKY group $(15.22 \pm 4.34$ vs. $11.85 \pm 3.21 \%, P<0.05)$, with no significant difference among the three drug-treated groups $(13.86 \pm 4.63,13.11 \pm 3.50$ and $13.45 \pm 4.15 \%$, respectively).
Effects on ultrastructure characterization of LV

Significant ultrastructure changes were found in the no treatment group, including abundant swollen myocardial cells, plentiful tough collagen fibers, dissolved myofilaments, disarrayed Z-line and swollen mitochondria (Figure 3). These abnormalities were markedly ameliorated in the three drug-treated groups. Stereology showed fewer 

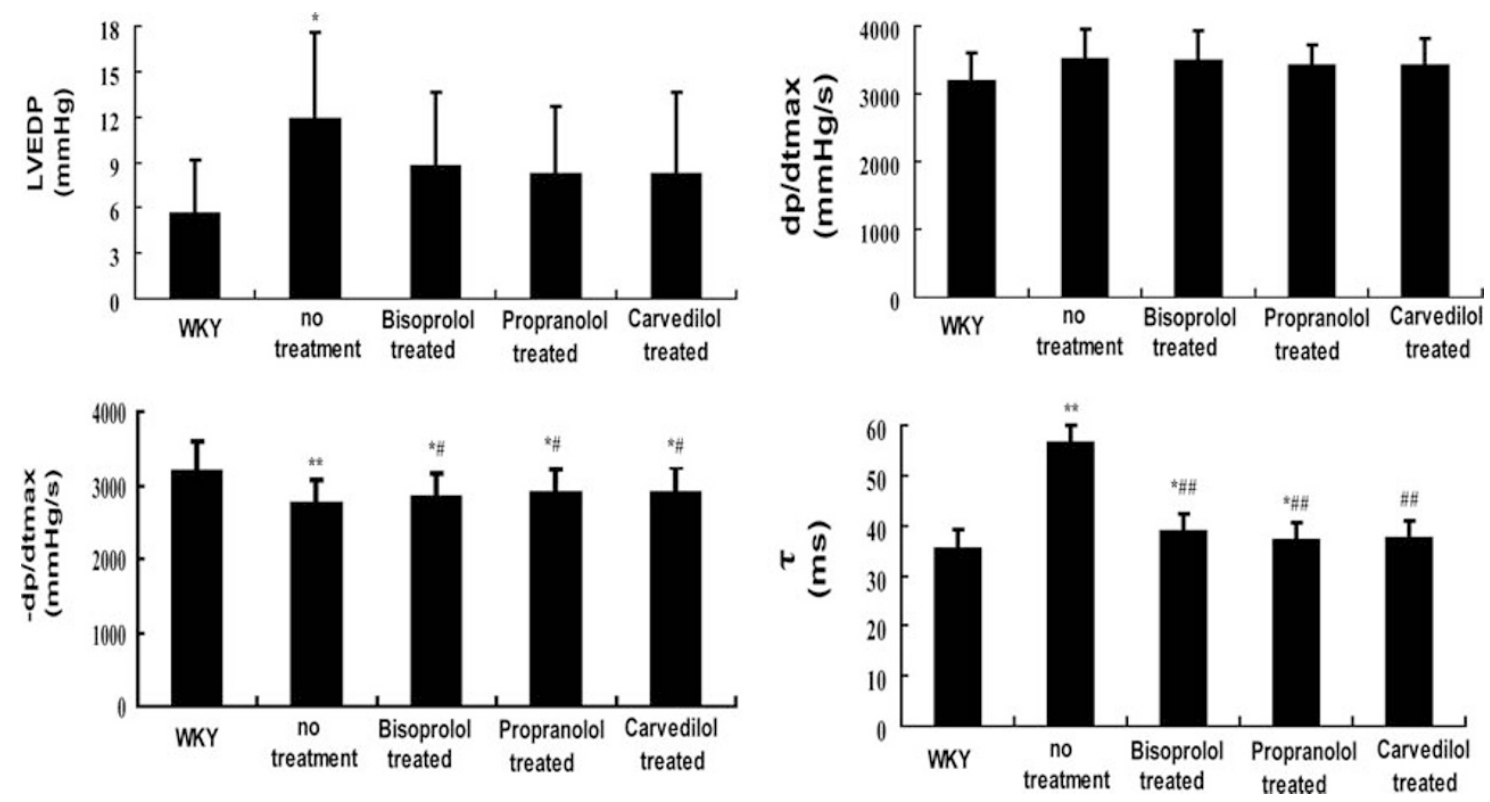

Figure 2 Hemodynamic measurements in five groups of rats. left ventricular(LV) end-diastolic was higher in the no treatment group than in the Wistar-Kyoto

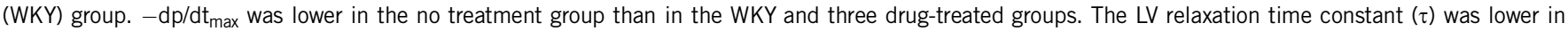
the WKY and three drug treated groups than in the no treatment group. ${ }^{*} P<0.05,{ }^{*} P<0.01$, vs. WKY group; ${ }^{\#} P<0.05$, ${ }^{\#} P<0.01$, vs. no treatment group.

collagen fibers in the three drug-treated groups than in the no treatment group $(P<0.05-0.01$, Figure 3$)$.

\section{Effects on cellular apoptosis and intracellular free $\mathrm{Ca}^{2+}$} concentration

In comparison with the WKY group, the no treatment and three drugtreated groups showed increased cellular apoptosis rates. All three drug-treated groups had lower apoptosis rates than the no treatment group $(P<0.05-0.01)$ and the apoptosis rate in the carvedilol-treated group was significantly lower than that of the other two drug-treated groups. The WKY group had lower intracellular free $\mathrm{Ca}^{2+}$ concentration than any other group $(P<0.01)$. As compared with the no treatment group, the three drug-treated groups showed decreased intracellular free $\mathrm{Ca}^{2+}$ concentrations $(P<0.05-0.01)$, with no significant difference among the three drug-treated groups (Figure 4 ).

\section{Effects on mRNA expression of AR subtypes}

The mRNA expression of AR- $\alpha_{1 \mathrm{~A}}$ and AR- $\alpha_{1 \mathrm{D}}$ did not differ among all five groups of rats (Figure 5). The mRNA expression of AR- $\alpha_{1 B}$ was significantly higher in the no treatment, bisoprolol-treated and propranolol-treated groups than in the WKY group. After treatment, the mRNA expression of AR- $\alpha_{1 B}$ was significantly lower in the carvediloltreated group than in the no treatment, bisoprolol-treated and propranolol-treated groups but did not differ from that in the WKY group. The mRNA expression of AR- $\beta_{1}$ and AR- $\beta_{2}$ was significantly lower in the no treatment and three drug-treated groups than in the WKY group. After treatment, however, the mRNA expression of AR- $\beta_{1}$ was higher in the three drug-treated groups than in the no treatment group but still lower than that of the WKY group (all $P<0.01$ ). Similarly, after treatment the expression of AR- $\beta_{2}$ was higher in the three drug-treated groups than in the no treatment group $(P<0.05-0.01)$, with a significantly stepwise increase in the bisoprolol-treated, propranolol-treated and carvedilol-treated groups $(P<0.05-0.01)$.
The mRNA expression of Gs $\alpha$ protein was significantly lower in the no treatment, bisoprolol-treated and propranolol-treated groups than in the WKY group $(P<0.01$, Figure 5$)$ but did not differ from that in the carvedilol-treated group. The mRNA expression of Gq $\alpha$ protein was lower in the propranolol-treated and carvedilol-treated groups than in the no treatment group (all $P<0.05$ ) but was higher in the no treatment and bisoprolol-treated groups than in the WKY group. The Gi $\alpha$ and G $\beta$ mRNA expression did not differ among the no treatment and three drug-treated groups.

\section{Effects of AR antagonist on expression of collagens and protein kinase}

The effects of AR antagonist on the levels of protein expression of collagen and protein kinases were examined by immunohistochemical staining and western blotting. The expression level of type I collagen was significantly lower in the WKY and three drug-treated groups than in the no treatment group $(P<0.05-0.01$, Figures 6 and 7$)$, with no significant differences among the three drug-treated groups. The expression level of type III collagen did not differ among any of the five groups of rats. The expression level of PKA, PKC- $\alpha$ and PKC- $\delta$ was higher in the no treatment group than in the WKY group $(P<0.01)$, and that of PKA was significantly lower in the three drug-treated groups than in the no treatment group $(P<0.05-0.01$, Figures 6 and 7), with no significant difference among the drugtreated groups. PKC- $\alpha$ and PKC- $\delta$ expression in the carvedilol-treated group was markedly lower than that of the no treatment group. The expression of $\mathrm{p} 38$-MAPK in the no treatment group and three drugtreated groups was higher than that in the WKY group $(P<0.01$, Figure 6) and was significantly lower in the carvedilol-treated group than in the no treatment group $(P<0.01$, Figure 7$)$.

\section{DISCUSSION}

In this study, we compared the effects of selective AR- $\beta_{1}$ antagonist bisoprolol, nonselective AR- $\beta_{1}$ and AR- $\beta_{2}$ antagonist propranolol and 

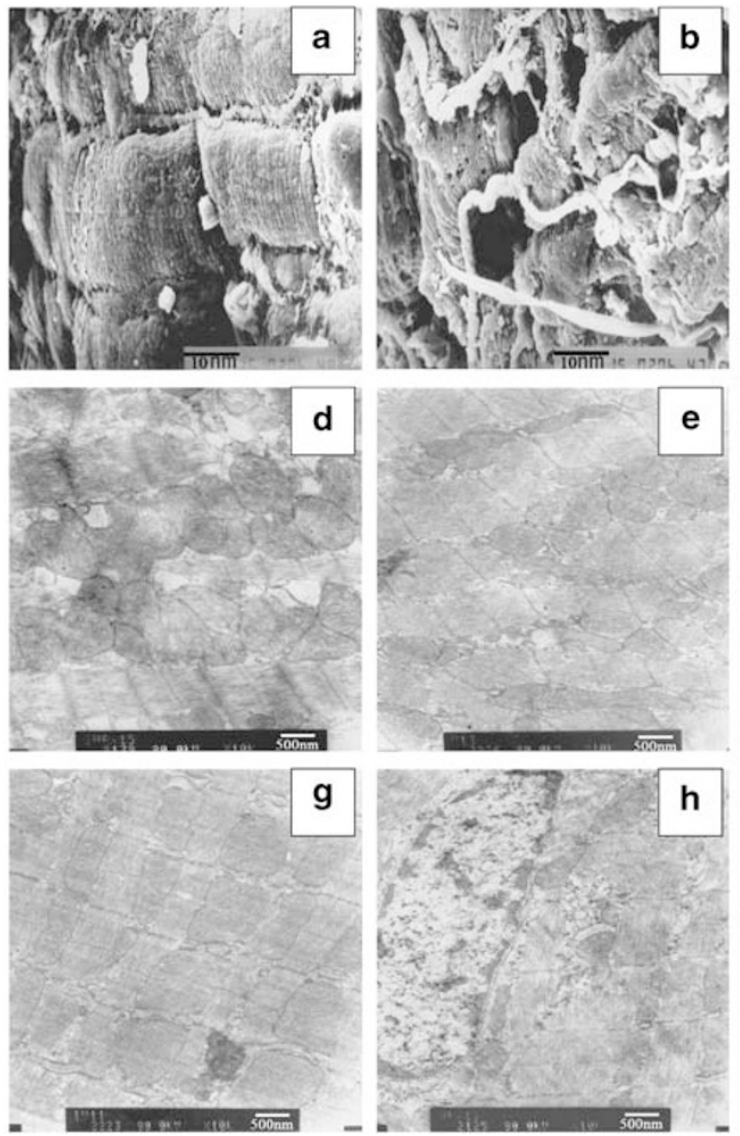
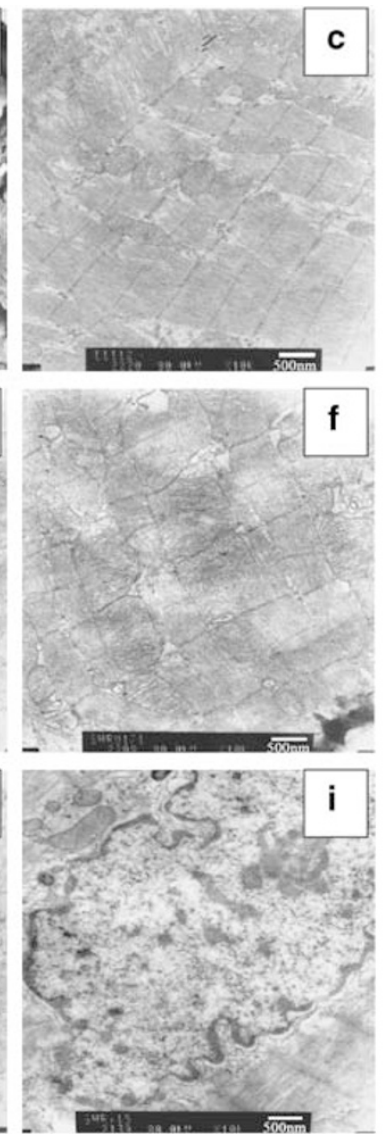


Figure 3 Electron microscopic images. (a) Scanning electron microscopic image of myocardial cells covered by few tough collagen fibers in the Wistar-Kyoto (WKY) group ( $\times 3500$ ); (b) Scanning electron microscopic image of myocardial cells covered by plentiful tough collagen fibers in the no treatment group ( $\times 3500$ ); (c) Transmission electron microscopic image of myocardial cells and mitochondria that line up in order with distinct Z-line in the WKY group ( $\times 10000)$; (d) Transmission electron microscopic image showing abundant swollen myocardial cells and mitochondria with disordered myofilaments in the no treatment group $(\times 10000)$; (e) Transmission electron microscopic image displaying less swollen myocardial cells and mitochondria in the bisoprololtreated group $(\times 10000)$; (f) Transmission electron microscopic image depicting less swollen myocardial cells and mitochondria in the propranolol-treated group $(\times 10000)$; $(\mathbf{g})$ Transmission electron microscopic image showing mildly swollen myocardial cells and mitochondria in the carvedilol-treated group $(\times 10000)$; (h, e) Transmission electron microscopic image showing normal perinuclear space in a myocardial cell of the WKY group $(\times 10000)$; (i) Transmission electron microscopic image showing widened perinuclear space in a myocardial cell of the no treatment group $(\times 10000)$. Bar graphs on the right show quantitative analysis of the relative contents of collagen and mitochondria. The relative content of collagen was lower in the three drug-treated groups than in the no treatment group. The relative content of mitochondria was higher in the no treatment group than in the WKY group. ${ }^{*} P<0.05$, ${ }^{* *} P<0.01$, vs. WKY group; ${ }^{\#} P<0.05,{ }^{\#} P<0.01$, vs. no treatment group.

combined AR- $\alpha_{1}$, AR- $\beta_{1}$ and AR- $\beta_{2}$ antagonist carvedilol on LV remodeling. Our major finding was that carvedilol was not superior to bisoprolol or propranolol in inhibiting LV remodeling and ameliorating LV diastolic dysfunction even though it had the largest effect on attenuating cardiocyte apoptosis, normalizing AR- $\alpha_{1 B}$ and Gs $\alpha$ expression and increasing AR- $\beta_{2}$ expression.

In patients with hypertension, LV remodeling is the key pathological process leading to heart failure. The mechanisms of LV remodeling involves both mechanical and neurohumoral factors. Mechanical factors include hypertrophy of myocardial cells, interstitial fibrosis and collagen accumulation, whereas neurohumoral factors contain catecholamine, angiotensin II, aldosterone, endothelin and cytokines, which accelerate the pathologic processes of LV remodeling. Therefore, identification of antihypertensive drugs that are most effective in inhibiting LV remodeling is of major importance in the prevention of heart failure secondary to hypertension.

AR- $\beta$ antagonists, either alone or in combination with other classes of antihypertensive agents, have had a long history of use in lowering high blood pressure. Bisoprolol, a highly selective $\beta_{1}$-adrenoceptor antagonist, is currently used to treat hypertension, atrial fibrilation, heart failure and coronary artery disease. Weiss et al. ${ }^{18}$ found that bisoprolol attenuated LV hypertrophy after a 8-week treatment in patients suffering with essential hypertension. Onodera et al. ${ }^{19}$ reached the same conclusion after a 4 -week treatment of a 12-week-old SHR. Propranolol is a nonselective $\beta$-adrenoceptor antagonist and blocks both AR- $\beta_{1}$ and AR- $\beta_{2}$ of the myocardium. However, the efficacy of propranolol in abating LV hypertrophy and interstitial fibrosis is controversial. Saragoca et al. ${ }^{20}$ reported that propranolol did not reverse cardiac hypertrophy in renal hypertensive rats. In contrast, Pacca et al. ${ }^{21}$ found that the propranolol attenuated cardiomyocyte hypertrophy and myocardial fibrosis in rats under long-term blockade of nitric oxide synthesis. Carvedilol is a combined AR- $\alpha_{1}, A R-\beta_{1}$ and AR- $\beta_{2}$ antagonist with potent antioxidant activity and has been used widely in the treatment of hypertension, angina and congestive heart failure. In many clinical and experimental studies, carvedilol has proved effective in reducing LV hypertrophy in humans and SHR. ${ }^{22}$

In this study, SHR as the animal model of spontaneous hypertension was used to compare the therapeutic effects of three different 

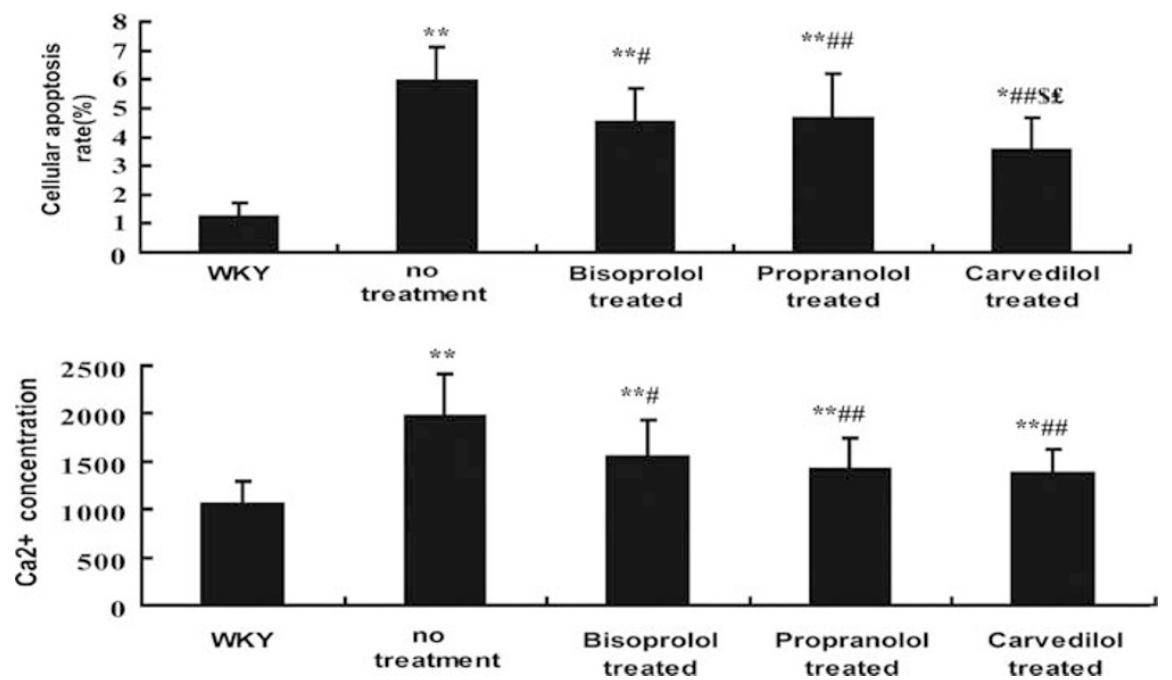

Figure 4 Cellular apoptosis rate and intracellular free $\mathrm{Ca}^{2+}$ concentration measured by flow cytometry. Apoptosis rate was higher in the no treatment and three drug-treated groups than in the Wistar-Kyoto (WKY) group but was lower in the three drug-treated groups than in the no treatment group, with the carvedilol-treated group having the lowest apoptotic rate. The intracellular free $\mathrm{Ca}^{2+}$ concentration was lower in the WKY group than in any other group, and was lower in the three drug-treated groups than in the no treatment group. ${ }^{*} P<0.05,{ }^{*}{ }^{*} P<0.01$, vs. WKY group; ${ }^{\#} P<0.05$, \#\# $P<0.01$, vs. no treatment group; ${ }^{\$} P<0.05$ vs. bisoprolol-treated group; ${ }^{£} P<0.05$ vs. propranolol-treated group.
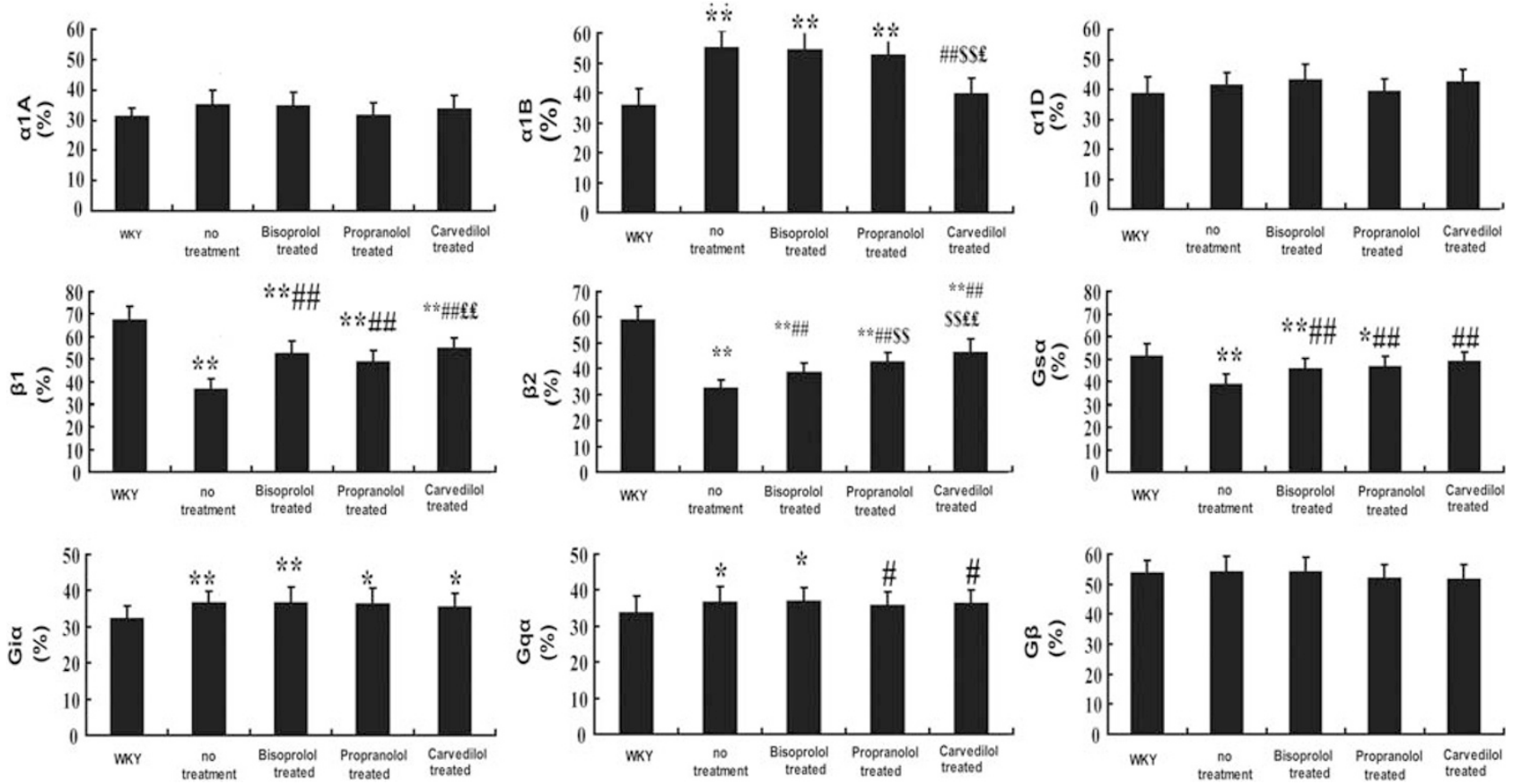

Figure 5 The mRNA expression of adrenergic receptor (AR) and G-protein subtypes. The mRNA expression of AR- $\alpha_{1 B}$ was lower in the Wistar-Kyoto (WKY) group than in the no treatment, bisoprolol-treated and propranolol-treated groups but did not differ from that in the carvedilol-treated group. The mRNA expression of $A R-\beta_{1}$ and AR- $\beta_{2}$ was lower in the no treatment and three drug-treated groups than in the WKY group but was higher in the three drug-treated groups than in the no treatment group. The mRNA expression of Gs $\alpha$ expression was higher in the WKY group than in the bisoprolol-treated and propranololtreated groups but did not differ from that in the carvedilol-treated group. The mRNA expression of Gi $\alpha$ was lower in the WKY group than in the any other group. The mRNA expression of Gq $\alpha$ was lower in WKY group than in the no treatment and bisoprolol-treated groups but did not differ from that in the propranolol-treated and carvedilol-treated groups. ${ }^{*} P<0.05$, ${ }^{*} P<0.01$, vs. WKY group; ${ }^{\#} P<0.05$, ${ }^{\# \#} P<0.01$, vs. no treatment group; $\$ \$ P<0.01$, vs. bisoprolol-treated group; ${ }^{£} P<0.05$, ${ }^{£ £} P<0.01$, vs. propranolol-treated group.

AR- $\beta$ antagonists. Our results showed that SBP was significantly lowered in all three drug-treated groups to the normal level of WKY rats 24-weeks after treatment. In addition, all drug-treated groups, as compared with the no treatment group, showed decreased LVMI and $\tau$ and increased $\mathrm{E} / \mathrm{A}$ ratio and $-\mathrm{dp} / \mathrm{dt}_{\max }$, which indicated that $\mathrm{LV}$ hypertrophy and diastolic dysfunction were greatly improved and all three AR antagonists had equal effects on LV remodeling. Moreover, ultrastructural analysis showed significantly decreased interstitial collagen content after antihypertensive treatment by the three AR antagonists, which was confirmed by histopathology and immuno- 

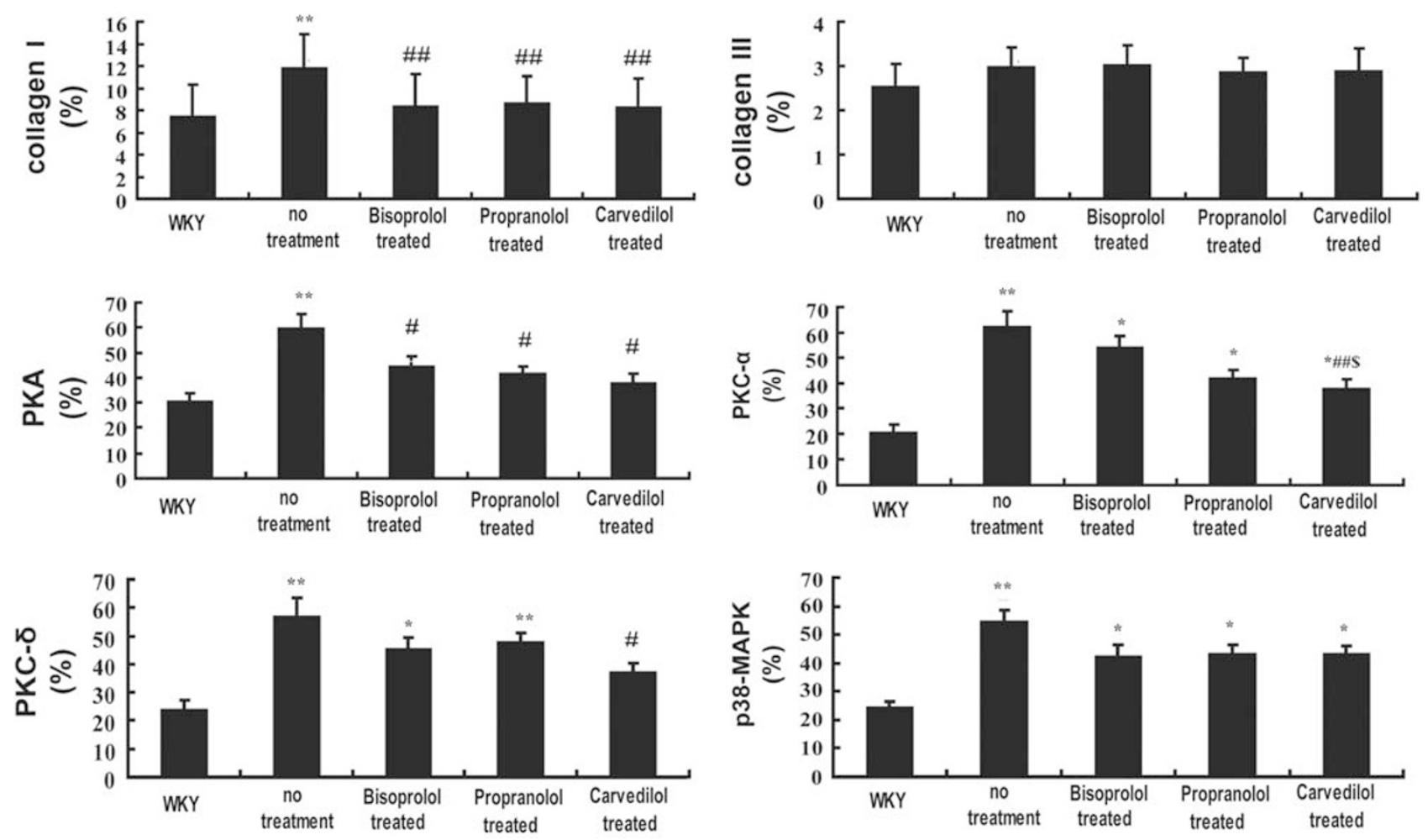

Figure 6 Quantitative analysis of immunohistochemical staining in five groups of rats. Protein expression of type I collagen was significantly lower in the Wistar-Kyoto (WKY) and the three drug-treated groups than in the no treatment group. The expression level of protein kinase(PK) PKA, PKC- $\alpha$ and (PK)C- $\delta$ was higher in the no treatment group than in the WKY group. Protein expression of PKA was significantly lower in the three drug-treated groups than in the no treatment group. PKC- $\alpha$ and PKC- $\delta$ expression in the carvedilol-treated group was lower than in the no treatment group. The expression of p38-MAPK was significantly lower in the in the WKY group than in the no treatment and three drug-treated groups. ${ }^{*} P<0.05,{ }^{*} P<0.01, v s$. WKY group; ${ }^{\#} P<0.05$, ${ }^{\# \# P}<0.01$, vs. no treatment group; ${ }^{\$} P<0.05$ vs. bisoprolol-treated group.

histochemistry. Immunohistochemistry also showed markedly decreased expression of type I collagen, with no significant difference in type III collagen content. Thus, AR antagonists inhibited LV remodeling by reducing interstitial fibrosis and accumulation of collagen, especially type I collagen. In addition, cellular apoptosis rate and intracellular free $\mathrm{Ca}^{2+}$ concentration were significantly lower in the drug-treated groups than in the no treatment group, suggesting that myocardial cell depletion and intracellular $\mathrm{Ca}^{2+}$ overload had important roles in myocardial remodeling. Compared with the other two medications, carvedilol appeared to have no greater effect on improving LV remodeling, except for having a higher effect on inhibition of cardiocyte apoptosis.

The ARs in the cardiovascular system include $\alpha$ and $\beta$ receptors with the former comprising of AR- $\alpha_{1}$ and AR- $\alpha_{2}$ and the later mainly of AR- $\beta_{1}$ and AR- $\beta_{2}$. The AR- $\alpha_{1}$ can be further classified into AR- $\alpha_{1 A}$, AR- $\alpha_{1 \mathrm{~B}}$ and AR- $\alpha_{1 \mathrm{D}}$ subtypes with AR- $\alpha_{1 \mathrm{~B}}$ is found to be dominant in the myocardium of mice. ${ }^{23,24}$ Wang et al..$^{25}$ reported that cardiac expression of constitutively active AR- $\alpha_{1 B}$ is detrimental in terms of cardiac hypertrophy and dysfunction after pressure overload and also that increased AR- $\alpha_{1 \mathrm{~A}}$ mRNA expression is not a feature of the hypertrophic response to hypertension. Vecchione et al. ${ }^{26}$ found no occurrence of high blood pressure and LV remodeling in response to noradrenaline stimulation in AR- $\alpha_{1 B}-/-$ mice. Chalothorn et al. ${ }^{27}$ showed that $\mathrm{AR}-\alpha_{1 \mathrm{~B}}$ was involved in the regulation of cardiac growth and contractile function, whereas AR- $\alpha_{1 D}$ was coupled to smooth muscle contraction and blood pressure regulation. A number of studies found that both AR- $\beta_{1}$ and AR- $\beta_{2}$ were downregulated in SHR. ${ }^{28-31}$ Chruscinski et al. ${ }^{32,33}$ reported that AR- $\beta_{1}$ had a dominant role in mediating vasodilation in mice. Hirota et al. ${ }^{34}$ found AR- $\beta_{2}$ stimulation improved inotropic and lusitropic function in the failing heart and Communal et al. ${ }^{35}$ reported that AR- $\beta_{2}$ inhibited cardiocyte apoptosis through a Gi-coupled pathway in rats. Thus, AR- $\beta_{1}$ and AR- $\beta_{2}$ have an important role in the regulation of cardiovascular function in mice and rats.

In this study, we found that the major changes of AR subtypes in the myocardium of SHR were increased expression of AR- $\alpha_{1 B}$ and decreased expression of AR- $\beta_{1}$ and AR- $\beta_{2}$. The mechanisms probably involve decreased AR- $\beta$ densities in response to enhanced sympathetic stimulation, and increased AR- $\alpha$ densities to compensate for impaired cardiac function in SHR. After treatment, we found mRNA expression of AR- $\alpha_{1 \mathrm{~B}}$ was normalized in the carvedilol-treated group as compared with the WKY group, but was not significantly different among the no treatment, bisoprolol-treated and propranolol-treated groups, which may reflect the fact that carvedilol directly blocks AR- $\alpha_{1}$, whereas bisoprolol and propranolol have no effects on AR- $\alpha_{1}$. On the other hand, bisoprolol, propranolol and carvedilol had no affect the expression of AR- $\alpha_{1 A}$ and AR- $\alpha_{1 D}$, which was consistent with previous studies. ${ }^{27}$ We also used bisoprolol to selectively block AR- $\beta_{1}$, and propranolol and carvedilol to nonselectively block AR- $\beta_{1}$ and AR- $\beta_{2}$ and found the expression levels of AR- $\beta_{1}$ and AR- $\beta_{2}$ increased significantly after treatment. Of note, carvedilol was superior to bisoprolol and propranolol in elevating the expression levels of AR- $\beta_{2}$. These therapeutic differences may be explained by the pharmacological discrepancies of the three AR- $\beta$ antagonists: bisoprolol has strong antagonism of AR- $\beta_{1}$ but weak antagonism of AR- $\beta_{2}$, propranolol has strong antagonism of both AR- $\beta_{1}$ and AR- $\beta_{2}$ and 



Figure 7 Western blotting analysis. Protein expression level of type I collagen was lower in the Wistar-Kyoto (WKY) and three drug-treated groups than in the no treatment group. Protein expression of PKC- $\alpha$ and PKC- $\delta$ was lower in the WKY and carvedilol-treated groups than in the no treatment group. Similarly, protein expression of p38-MAPK was lower in the WKY and carvedilol-treated groups than in the no treatment group. ${ }^{*} P<0.05,{ }^{* *} P<0.01, v s$. WKY group; ${ }^{\#} P<0.05$, ${ }^{\#} P<0.01$, vs. no treatment group; $\$ \$ P<0.01$, vs. bisoprolol-treated group.

carvedilol has stronger antagonism of AR- $\beta_{1}$ and AR- $\beta_{2}$. Blockade of AR- $\beta_{1}$ and AR- $\beta_{2}$ attenuated sympathetic stimulations and resulted in increased myocardial densities of these receptors.

$\mathrm{G}$ protein-coupled receptors are important downstream signaling molecules of AR activation. ${ }^{36}$ Signaling pathways initiated by AR- $\alpha_{1}$ involve the activation of the heterotrimeric G-protein, Gq, which elicits the accumulation of diacylglycerol and inositol 1,4,5-triphosphate and activates PKC and MAPKs. ${ }^{37}$ Dempsey et al. ${ }^{38}$ found that cardiac myocytes contain at least six different PKC isozymes but preconditioning results in activation of only two isozymes, PKC- $\delta$ and PKC- $\varepsilon$. Quantitation of PKC-isoform expression showed the dominance of the $\mathrm{Ca}^{2+}$-dependent PKC $\alpha$ over PKC- $\delta$ and PKC- $\varepsilon$. PKC- $\alpha$ is the single isozyme that translocates to the contractile system on $\mathrm{Ca}^{2+}$ stimulation in the rat heart, suggesting a unique physiological role for PKC $\alpha$ in the $\mathrm{Ca}^{2+}$-dependent regulation of myofibrillar contractility. ${ }^{39,40}$ The $\alpha$-subunit of Gq is a well-established mediator of hypertrophic growth in neonatal cardiomyocytes and in mouse hearts. Studies have found that although aortic AR- $\alpha_{1 \mathrm{~A}}, \mathrm{AR}-\alpha_{1 \mathrm{~B}}$ and AR- $\alpha_{1 \mathrm{D}}$ are associated with Gq $\alpha, A R-\alpha_{1 B}$ is also linked to Go $\alpha$ and the couple AR- $\alpha_{1 B}-G o \alpha$ mediates the contractile response of rat aorta. ${ }^{41,42}$ Although AR- $\beta$ binding to $\mathrm{Gs}$ and Gi-coupled receptors stimulate adenylyl cyclase and induce accumulation of cyclic adenosine monophosphate and activation of PKA, the $\alpha$-subunit of Gs $(\mathrm{Gs} \alpha)$ and Gi $(\mathrm{Gi} \alpha)$ has the main role. In the vasculature, these pathways have opposite effects: the $\mathrm{Gq}$ cascade results in the constriction of blood vessels, whereas the Gs and Gi signals mediate vasodilation. Both pathways have been shown to mediate hypertrophy in myocardial cells. ${ }^{43,44}$ In this study, after AR- $\alpha_{1}$ blockade with carvedilol, the expression of Gq $\alpha$ protein, PKC- $\alpha$ and PKC- $\delta$ was decreased significantly in the carvedilol-treated group, which suggested that Gq $\alpha$, PKC- $\alpha$ and PKC- $\delta$ were the main molecules linked to $\mathrm{AR}-\alpha_{1}$ in the signal transduction pathway. In contrast, the expression of AR- $\beta_{1}$ and AR- $\beta_{2}$ was increased after treatment, followed by a normalized Gs $\alpha$ protein expression and decreased PKA level, and these effects were the most significant in the carvediloltreated group. Therefore, carvedilol treatment appeared to be the most effective in counteracting the imbalance between AR- $\alpha$ and AR- $\beta$ in SHR among the three AR antagonists used in this study.

Recent studies have confirmed that cardiocyte apoptosis is a critical event in the transition between compensatory cardiac hypertrophy and heart failure. ${ }^{34}$ Catecholamine, released by activated sympathetic system, has been implicated in the progressive deterioration of the failing heart. Communal et al. ${ }^{35}$ showed that norepinephrine, functioning through AR- $\beta_{1}$ pathway, induces cardiac apoptosis by phosphorylation of L-type $\mathrm{Ca}^{2+}$ channels by activation of PKA. ${ }^{35}$ Increased cytosolic $\mathrm{Ca}^{2+}$ levels affects mitochondrial membrane permeability and triggers the release of apoptogenic factors, including caspase- 9 from damaged mitochondria. In this study, we found abundant swollen mitochondria with disordered myofilaments in the no treatment group, which was markedly ameliorated after treatment together with a reduced intracellular free $\mathrm{Ca}^{2+}$ concentration. Reduction of the intracellular $\mathrm{Ca}^{2+}$ concentration at resting state by the treatment of AR- $\beta$ antagonists has been reportedly associated with restoration of the cardiac ryanodine receptor $(\mathrm{RyR} 2) / \mathrm{Ca}^{2+}$ release channel function that regulates cardiac excitation-contraction coupling. ${ }^{45}$ Further 
evidence of cardiocyte apoptosis by activation of the AR- $\beta_{1}$ signaling pathway was derived from isoproterenol-treated rat hearts ${ }^{46}$ and transgenic mice overexpressing $\mathrm{Gs} \alpha^{47}$ or $\mathrm{Gq} \alpha{ }^{48}$ In this study, we found that the intracellular free $\mathrm{Ca}^{2+}$ concentration and the expression levels of PKA, PKC- $\alpha$, PKC- $\delta$ and p38-MAPK were substantially decreased after administration of AR antagonists, particularly in the carvedilol-treated group, which may have contributed to the antiapoptotic effects of these medications.

Our study contains several limitations. First, we did not specifically investigate the effects of AR- $\alpha_{1 A}, A R-\alpha_{1 B}$ and AR- $\alpha_{1 D}$ subtypes on hypertension because drugs that selectively block these AR subtypes are not available at this time. Second, the antioxidative effects of carvedilol was not assessed, although these effects may have contributed to the antiapoptotic benefits. Third, we did not measure the protein expression levels of AR subtypes and $G$ proteins although we did measure the protein expression levels of PKA, PKC- $\alpha$, PKC- $\delta$ and p38-MAPK, the downstream signaling molecules of AR subtypes, which correlated well with the mRNA expression levels of AR subtypes and $G$ proteins. Finally, previous studies reported that only the rat heart had high expression of AR- $\alpha_{1 B}$ as compared with human and other animal species. ${ }^{22}$ Therefore, our finding that carvedilol effectively blocks $\mathrm{AR}-\alpha_{1}$ cannot be extrapolated to human or other animals.

In conclusion, treatment with bisoprolol, propranolol and carvedilol substantially ameliorates LV remodeling and diastolic dysfunction in SHR and carvedilol is not superior to bisoprolol and propranolol in these therapeutic effects, although carvedilol is advantageous in attenuating cardiocyte apoptosis, normalizing AR- $\alpha_{1 \mathrm{~B}}$ and Gs $\alpha$ expression and increasing AR- $\beta_{2}$ expression.

\section{CONFLICT OF INTEREST}

The authors declare no conflict of interest.

\section{ACKNOWLEDGEMENTS}

This study was supported by the National 973 Basic Research Program of China (No.2009CB521900), the National High-Tech Research and Development Program of China (No.2006AA02A406), the Program of Introducing Talents of Discipline to Universities (No.B07035), the State Key Program of National Natural Science of China (No. 60831003), the National Natural Science Foundation of China (No. 30670873, No. 30900607, No. 30772810, No.30871040, 30971216) and Grants from the Natural Science Foundation of Shandong Province (Y2008C17).

1 Asai T, Kushiro T, Fujita H, Kanmatsuse K. Different effects on inhibition of cardiac hypertrophy in spontaneously hypertensive rats by monotherapy and combination therapy of adrenergic receptor antagonists and/or the angiotensin II type 1 receptor blocker under comparable blood pressure reduction. Hypertens Res 2005; 28: 79-87.

2 Sever P. New Hypertension Guidelines from the National Institute for Health and Clinical Excellence and the British Hypertension Society. J Renin Angiotensin Aldosterone Syst 2006; 7: 61-63.

3 Mancia G, Laurent S, Agabiti-Rosei E, Ambrosioni E, Burnier M, Caulfield MJ, Cifkova R, Clément D, Coca A, Dominiczak A, Erdine S, Fagard R, Farsang C, Grassi G, Haller H, Heagerty A, Kjeldsen SE, Kiowski W, Mallion JM, Manolis A, Narkiewicz K, Nilsson P, Olsen MH, Rahn KH, Redon J, Rodicio J, Ruilope L, Schmieder RE, Struijker-Boudier HA, van Zwieten PA, Viigimaa M, Zanchetti A. Reappraisal of European guidelines on hypertension management: a European Society of Hypertension Task Force document. J Hypertens 2009; 27: 2121-2158.

4 Keys JR, Zhou RH, Harris DM, Druckman CA, Eckhart AD. Vascular smooth muscle overexpression of $\mathrm{G}$ protein-coupled receptor kinase 5 elevates blood pressure, which segregates with sex and is dependent on $\mathrm{G}_{i}$-mediated signaling. Circulation 2005; 112 : 1145-1153.

5 Yamazaki T, Komuro I, Zou Y, Kudoh S, Shiojima I, Hiroi Y, Mizuno T, Aikawa R, Takano $\mathrm{H}$, Yazaki Y. Norepinephrine induces the raf-1 kinase/mitogen-activated protein kinase cascade through both alpha 1- and beta-adrenoceptors. Circulation 1997; 95: 1260-1268.

6 Asai K, Yang GP, Geng YJ, Takagi G, Bishop S, Ishikawa Y, Shannon RP, Wagner TE, Vatner DE, Homcy CJ, Vatner SF. Beta-adrenergic receptor blockade arrests myocyte damage and preserves cardiac function in the transgenic G(salpha) mouse. J Clin Invest 1999; 104: 551-558.

7 Iwata M, Yoshikawa T, Baba A, Anzai T, Nakamura I, Wainai Y, Takahashi T, Ogawa S. Autoimmunity against the second extracellular loop of beta(1)-adrenergic receptors induces beta-adrenergic receptor desensitization and myocardial hypertrophy in vivo. Circ Res 2001; 88: 578-586.

8 Mougenot N, Médiani O, Lechat P. Bisoprolol and hydrochlorothiazide effects on cardiovascular remodeling in spontaneously hypertensive rats. Pharmacol Res 2005; 51: 359-365.

9 Haeusler G, Schliep HJ, Schelling P, Becker KH, Klockow M, Minck KO, Enenkel HJ, Schulze E, Bergmann R, Schmitges CJ, Seyfried C, Harting J. High $B_{1}$-selectivity and favourable pharmacokinetics as the outstanding properties of bisoprolol. J Cardiovasc Pharmacol 1986; 8: S2-S15.

10 Yaoita H, Sakabe A, Maehara K, Maruyama Y. Different effects of carvedilol, metoprolol and propranolol on left ventricular remodeling after coronary stenosis or after permanent coronary occlusion in rats. Circulation 2002; 105: 975-980.

11 Devereux RB. Detection of left ventricular hypertrophy by M-mode echocardiography. Anatomic validation, standardization, and comparison to other methods. Hypertension 1987; 9: II9-126.

12 Weiss JL, Frederiksen JW, Weisfeldt ML. Hemodynamic determinants of the timecourse of fall in canine left ventricular pressure. J Clin Invest 1976; 58: 751-760.

13 Mandarim-de-Lacerda CA. Stereological tools in biomedical research. An Acad Bras Cienc 2003; 75: 469-486.

14 Login GR, Ku TC, Dvorak AM. Rapid primary microwave-aldehyde and microwaveosmium fixation: improved detection of rat parotid acinar cell secretory granule alphaamylase using a post-embedding immunogold ultrastructural morphometric analysis. J Histochem Cytochem 1995; 43: 515-523.

15 Brette F, Sallé L, Orchard CH. Quantification of calcium entry at the T-tubules and surface membrane in rat ventricular myocytes. Biophys J 2006; 90: 381-389.

16 Oyama Y, Chikahisa L, Kanemaru K, Nakata M, Noguchi S, Nagano T, Okazaki E, Hirata A. Cytotoxic actions of FTY720, a novel immunosuppressant, on tyhmocytes and brain neurons dissociated from the rat. JPN J Pharmacol 1998; 76: 377-385.

17 Livak KJ, Schmittgen TD. Analysis of relative gene expression data using real-time quantitative PCR and the 2(-delta delta C(T)) method. Methods 2001; 25: 402-408.

18 Weiss RJ, Rauscher A, Shaw D. Effect of bisoprolol and atenolol on left ventricular mass in patients with essential hypertension. Am J Ther 1994; 1: 81-85.

19 Onodera T, Okazaki F, Miyazaki H, Minami S, Ito T, Seki S, Taniguchi M, Taniguchi I, Mochizuki S. Perindopril reverses myocyte remodeling in the hypertensive heart. Hypertens Res 2002; 25: 85-90.

20 Saragoca MA, Cezaretti ML, Tavares A, Bessa AM, Almeida JB, Amorin MP, Ramos OL. Pindolol, not propranolol, reverses cardiac hypertrophy in renal hypertensive rats. Hypertension 1988; 11: 189-192.

21 Pacca SR, de Azevedo AP, De Oliveira CF, De Luca IM, De Nucci G, Antunes E. Attenuation of hypertension, cardiomyocyte hypertrophy, and myocardial fibrosis by beta-adrenoceptor blockers in rats under long-term blockade of nitric oxide synthesis. J Cardiovasc Pharmacol 2002; 39: 201-207

22 Carreira RS, Monteiro P, Gon Alves LM, Providencia LA. Carvedilol: just another betablocker or a powerful cardioprotector? Cardiovasc Hematol Disord Drug Targets 2006; 6: 257-266.

23 Brodde OE, Michel MC. Adrenergic and muscarinic receptors in the human heart. Pharmacol Rev 1999; 51: 651-690.

24 Cavalli A, Lattion AL, Hummler E, Nenniger M, Pedrazzini T, Aubert JF. Decreased blood pressure response in mice deficient of the $\alpha_{1 \mathrm{~B}}$-adrenergic receptor. Proc Natl Acad Sci USA 1997; 94: 11589-11594.

25 Wang BH, Du XJ, Autelitano DJ, Milano CA, Woodcock EA. Adverse effects of constitutively active $\alpha_{1 \mathrm{~B}}$-adrenergic receptors after pressure overload in mouse hearts. Am J Physiol Heart Circ Physiol 2000; 279: H1079-H1086.

26 Vecchione C, Fratta L, Rizzoni D, Notte A, Poulet R, Porteri E, Frati G, Guelfi D, Trimarco V, Mulvany MJ, Agabiti-Rosei E, Trimarco B, Cotecchia S, Lembo G. Cardiovascular influences of alphalb-adrenergic receptor defect in mice. Circulation 2002; 105: 1700-1707.

27 Chalothorn D, McCune DF, Edelmann SE, Tobita K, Keller BB, Lasley RD, Perez DM, Tanoue A, Tsujimoto G, Post GR, Piascik MT. Differential cardiovascular

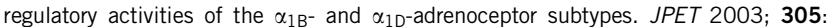
1045-1053.

28 Ren J, Smude BW, Pavlik ML, Brown RA. Diminished cardiac contractile response to tetrahydropapaveroline in hypertension: role of beta-adrenoceptors and intracellular $\mathrm{Ca}^{2+}$. Alcohol 2000; 21: 149-159.

29 Witte K, Parsa-Parsi R, Vobig M, Lemmer B. Mechanisms of the circadian regulation of beta-adrenoceptor density and adenylyl cyclase activity in cardiac tissue from normotensive and spontaneously hypertensive rats. J Mol Cell Cardiol 1995; 27: 1195-1202.

30 Atkins FL, Bing OH, DiMauro PG, Conrad CH, Robinson KG, Brooks WW. Modulation of left and right ventricular beta-adrenergic receptors from spontaneously hypertensive rats with left ventricular hypertrophy and failure. Hypertension 1995; 26 : 78-82.

31 K-Laflamme A, Oster L, Cardinal R, de Champlain J. Effects of renin-angiotensin blockade on sympathetic reactivity and beta-adrenergic pathway in the spontaneously hypertensive rat. Hypertension 1997; 30: 278-287. 
32 Chruscinski A, Brede ME, Meinel L, Lohse MJ, Kobilka BK, Hein L. Differential distribution of beta-adrenergic receptor subtypes in blood vessels of knockout mice lacking beta(1)-or beta(2)-adrenergic receptors. Mol Pharmacol 2001; 60: 955-962.

33 Bohm M, Ettelbruck S, Flesch M, van Gilst WH, Knorr A, Maack C, Pinto YM, Paul M, Teisman AC, Zolk O. Beta-adrenergic signal transduction following carvedilol treatment in hypertensive cardiac hypertrophy. Cardiovasc Res 1998; 40: 146-155.

34 Hirota H, Chen J, Betz UA, Rajewsky K, Gu Y, Ross Jr J, Müller W, Chien KR. Loss of a gp 130 cardiac muscle cell survival pathway is a critical event in the onset of heart failure during biomechanical stress. Cell 1999; 97: 189-198.

35 Communal C, Singh K, Pimentel DR, Collucci WS. Norepinephrine stimulates apoptosis in adult rat ventricular myocytes by activation of the $\beta$-adrenergic pathway. Circulation 1998; 98: 1329-1334.

36 Wettschureck N, Offermanns S. Mammalian G proteins and their cell type specific functions. Physiol Rev 2005; 85: 1159-1204.

37 Kawamura S, Yoshida K, Miura T, Mizukami Y, Matsuzaki M. Ischemic preconditioning translocates PKC-delta and -epsilon, which mediate functional protection in isolated rat heart. Am J Physiol 1998; 275: H2266-H2271.

38 Dempsey EC, Newton AC, Mochly-Rosen D, Fields AP, Reyland ME, Insel PA, Messing RO. Protein kinase $C$ isozymes and the regulation of diverse cell responses. Am J Physiol Lung Cell Mol Physiol 2000; 279: L429-L438.

39 Mackay K, Mochly-Rosen D. Localization, anchoring, and functions of protein kinase C isozymes in the heart. J Mol Cell Cardiol. 2001; 33: 1301-1307.

40 Molnár A, Borbély A, Czuriga D, Ivetta SM, Szilágyi S, Hertelendi Z, Pásztor ET, Balogh A, Galajda Z, Szerafin T, Jaquet K, Papp Z, Edes I, Tóth A. kinase C contributes to the maintenance of contractile force in human ventricular cardiomyocytes. J Biol Chem 2009; 284: 1031-1039.

41 O-Uchi J, Sasaki H, Morimoto S, Kusakari Y, Shinji H, Obata T, Hongo K, Komukai K, Kurihara S. of alpha1-adrenoceptor subtypes with different $\mathrm{G}$ proteins induces opposite effects on cardiac L-type $\mathrm{Ca}^{2+}$ channel. Circ Res 2008; 102: 1378-1388.

42 Zhu M, Gach AA, Liu G, Xu X, Lim CC, Zhang JX, Mao L, Chuprun K, Koch WJ, Liao R, Koren G, Blaxall BC, Mende U. Enhanced calcium cycling and contractile function in transgenic hearts expressing constitutively active $\mathrm{G}$ alpha o* protein. Am J Physiol Heart Circ Physiol 2008; 294: H1335-H1347.

43 Keys JR, Greene EA, Koch WJ, Eckhart AD. Gq-coupled receptor agonists mediate cardiac hypertrophy via the vasculature. Hypertension 2002; 40: 660-666.

44 Zaugg M, Xu W, Lucchinetti E, Shafiq SA, Jamali NZ, Siddiqui MAQ. Adrenergic receptor subtypes differentially affect apoptosis in adult rat ventricular myocytes. Circulation 2000; 102: 344-350.

45 Reiken S, Wehrens XH, Vest JA, Barbone A, Klotz S, Mancini D, Burkhoff D, Marks AR. Beta-blockers restore calcium release channel function and improve cardiac muscle performance in human heart failure. Circulation 2003; 107: 2459-2466.

46 Shizukuda Y, Buttrick PM, Geenen DL, Borczuk AC, Kitsis RN, Sonnenblick EH. Beta-adrenergic stimulation causes cardiocyte apoptosis: influence of tachycardia and hypertrophy. Am J Physiol. 1998; 275: H961-H968.

47 Geng YJ, Ishikawa Y, Vatner DE, Wagner TE, Bishop SP, Vatner SF, Homcy CJ. Apoptosis in cardiac myocytes in Gsa transgenic mice. Circ Res. 1999; 84: 34-42.

48 Adams JW, Sakata Y, Davis MG, Sah VP, Wang Y, Liggett SB, Chien KR, Brown JH, Dorn II GW. Enhanced Gaq signaling: a common pathway mediates cardiac hypertrophy and apoptotic heart failure. Proc Natl Acad Sci USA 1998; 95: 10140-10145. 